American Journal of Pharmaceutical Education 2020; 84 (3) Article 7700.

\title{
COMMENTARY
}

\section{Is It Time for a Quality Rating System for Colleges of Pharmacy?}

\author{
David P. Nau, PhD, ${ }^{a}$ Benjamin Aronson, $\mathrm{PhD},{ }^{\mathrm{b}}$ Terri Warholak, $\mathrm{PhD}^{\mathrm{c}}$ \\ ${ }^{a}$ University of Wyoming, School of Pharmacy, Laramie, Wyoming \\ ${ }^{\mathrm{b}}$ Ohio Northern University, Raabe College of Pharmacy, Ada, Ohio \\ ${ }^{c}$ University of Arizona, College of Pharmacy, Tucson, Arizona
}

Submitted May 30, 2019; accepted October 4, 2019; published March 2020.

\begin{abstract}
The quality of educational programs, including Doctor of Pharmacy (PharmD) programs, has largely escaped the societal trend towards public reporting. Recent criticisms of pharmacy academia by practitioners should prompt us to reexamine how the quality of pharmacy education is measured and reported to the public. In supporting greater transparency related to quality, important questions that should be addressed include: Is the current public reporting of quality indicators for pharmacy schools sufficient for determining the quality of education provided by a school? Can a quality rating system be developed that will not only provide a valid assessment of quality, but also be easy to interpret by potential applicants and employers? The intent of this commentary is to initiate a discussion centered around this issue and to encourage the development of a new measure of pharmacy school quality.
\end{abstract}

Keywords: quality, rankings, North American Pharmacist Licensure Examination

The United States healthcare system is moving forward with quality ratings of health plans, providers, and institutions. For example, the Medicare Star Rating system has been in place for a decade and has profoundly impacted the attentiveness of Medicare plans to quality measures. ${ }^{1}$ The trend in the star rating measures shows that plans have improved on those dimensions of quality that are measured and publicly reported. As a consequence, the Medicare population and therefore society as a whole have benefitted from improved quality.

The quality of educational programs, including Doctor of Pharmacy (PharmD) programs, has largely escaped the societal trend towards the release of publicly available quality reports. Healthcare employers and the general public rely on regulatory bodies (ie, state boards of pharmacy) to ensure pharmacists possess the professional competence necessary to practice pharmacy. In turn, regulators use the North American Pharmacist Licensure Examination (NAPLEX) and Multistate Pharmacy Jurisprudence Examination (MPJE) to evaluate the professional competence of pharmacists. Yet, more broadly, there is a relative absence of publicly reported quality indicators for PharmD programs. Recruiters for residency programs or employers seeking new graduates may have limited ability to assess the relative quality of education received by candidates or the likelihood a new

Corresponding Author: David Nau, School of Pharmacy, University of Wyoming, 1000 E. University Ave., Laramie, WY 82071. Tel: 859-537-8462. Email: dnau@uwyo.edu. graduate will pass the NAPLEX. Furthermore, applicants to PharmD programs have very limited information available to evaluate the relative quality of schools and colleges of pharmacy.

At the same time, there has been growing concern regarding the quality of the education provided by pharmacy schools. Many practitioners have pointed to the growth in the number of schools and dramatic increase in numbers of graduates as the root cause of their concerns. ${ }^{2,3}$ While some of these concerns may be rooted in the oversupply of pharmacists in several regions of the country $^{4,5}$ and the increasing difficulty for new graduates to find employment in these oversupplied markets, we have also anecdotally heard complaints from employers as well as residency preceptors regarding the skills of new graduates. The National Association of Boards of Pharmacy's (NABP's) update of the NAPLEX blueprint for 2016 resulted in lower passing rates on the first attempt by candidates and has resulted in greater differences in pass rates between schools. ${ }^{6}$ This has led to concern over the growing number of graduates who are unable to pass the NAPLEX and become licensed as pharmacists. It has also highlighted differences between schools, and we have heard some employers and residency preceptors express reluctance to hire new graduates from schools with below average pass rates on the NAPLEX. The growing frustration with this situation has led to a petition on Change.org (Change.org, Inc., San Francisco, CA) signed by over 22,000 persons that demands change in the accreditation of pharmacy schools. The petition included a 


\section{American Journal of Pharmaceutical Education 2020; 84 (3) Article 7700.}

call for the Accreditation Council for Pharmacy Education (ACPE) to require each school to maintain a NAPLEX pass rate above $80 \%$ to maintain their accreditation. ${ }^{7}$

Schools and colleges of pharmacy, along with the ACPE and the American Association of Colleges of Pharmacy (AACP), should address these concerns and support greater transparency regarding the quality of PharmD education. In supporting greater transparency related to quality, important questions that should be addressed include: Is the current public reporting of quality indicators for pharmacy schools sufficient for determining the quality of education provided by a school? Can a quality rating system be developed that will not only provide a valid assessment of quality, but also be easy to interpret by potential applicants and employers?

\section{Limitations of Existing Quality Indicators}

The current quality-related metrics available to the public include the accreditation status of a school, the US News \& World Report (USNWR) annual rankings, and the annual NAPLEX pass rates. However, each of these existing sources of quality-related data have their limitations. For example, the accreditation status of schools is of minimal use in differentiating between accredited institutions unless there is a significant deficit noted in the accreditation status (such as probation). It is our belief that that applicants will be unlikely to know that a school is on probation unless the school openly discloses this information to potential applicants.

The USNWR rankings of pharmacy school depends solely on the ratings of the deans of the schools of pharmacy. ${ }^{8}$ Only $40 \%$ of pharmacy deans participated in the 2015 survey by USNWR, and there is not a validated rubric for deans to use in assigning a rating to their school. Each respondent to the USNWR dean's survey is asked to provide a rating for each pharmacy school on a scale of 1 to 5 wherein 5 is the highest rating. Thus, each dean uses whatever criteria he or she chooses and which may be based heavily on reputation of the institution for areas outside the educational quality of the PharmD program (eg, research).

In 2012, Ascione pointed out the "folly" of chasing the USNWR ranking because of the perceived lack of validity of the rankings. ${ }^{9}$ He noted that deans are unlikely to know much about the educational strategies and quality of education delivered by other schools, particularly newer schools. Thus, deans tend to rely on the prior rankings of schools, the cadre of academic leaders from each school, or the amount of federal research support received by the school. This may explain why the topranked schools tend to be those with the largest research programs and largest number of faculty members.
In 2016, NABP initiated changes in the NAPLEX and additional changes were made in 2017 and 2018. The new version of the NAPLEX is longer and uses more casebased assessments. ${ }^{6}$ The first-attempt pass rates for the new NAPLEX dropped significantly from the prior version and revealed substantial differences in pass rates between schools. The national average pass rates for first attempts over the three years of the new NAPLEX have been: $85.9 \%$ (2016), 88.0\% (2017) and 89.5\% (2018). For 2018 graduates, the first-attempt pass rates varied widely between schools, with a range of $57.8 \%$ to $100 \%$. Nineteen schools had a first-attempt pass rate less than $80 \%$ for 2018 graduates.

Research by Mattingly and colleagues showed that the NAPLEX pass rate may be an acceptable metric for comparing schools of pharmacy. ${ }^{10}$ They used a Delphi method along with surveys to gather input from deans on the most preferable metrics for evaluating the quality of PharmD education. The deans did not prefer the USNWR rankings but highly ranked several other potential metrics including NAPLEX scores, student satisfaction, and job placement. They noted that job placement was not currently a metric that varied much between schools; however, this may change as more states experience an oversupply of pharmacists.

Because the NAPLEX pass rates vary between schools and are consistently tracked by NABP, these rates may be a reasonable starting point for a new rating methodology. However, pass rates are only useful if they are easily accessible to applicants or employers and can easily be compared to national or regional benchmarks. The ACPE requires schools to disclose their pass rates on the school website along with other selected metrics; however, our non-systematic review of websites revealed that quality information is often not easily found. An applicant may have to wade through several layers of webpages to find the information. Also, there is considerable variation in the timing of updates to the metrics and the way in which the metrics are reported. Understandably, schools attempt to "spin" the quality metrics in the most positive way by selecting timeframes or comparators that make the school appear as favorable as possible.

Some may question whether the USNWR rankings are already reflective of the quality of PharmD education as judged by the NAPLEX pass rates for schools. To investigate the relationship of NAPLEX pass rates and USNWR rank, we created a ranking system for schools based on NAPLEX pass rates. We calculated the threeyear mean (2016-2018) for each school on the NAPLEX first-attempt pass rate. By using the three-year mean, we minimize the year-to-year variability in pass rates. We then ranked the schools in order of their mean pass rate. 


\section{American Journal of Pharmaceutical Education 2020; 84 (3) Article 7700.}

As seen in Table 1, there are many schools that are ranked highly by USNWR but which rank much lower on NAPLEX pass rates. While all of the schools ranked in the top 10 by USNWR had mean NAPLEX pass rates that were above the national average, several of these topranked schools did not finish in the "top 50" for NAPLEX ranking. Conversely, Table 2 reveals that many of the schools with a high NAPLEX pass rate do not have a high ranking in USNWR. For example, South Dakota State University had the top-ranked NAPLEX pass rate for 2016-2018 but was ranked $70^{\text {th }}$ in USNWR.

\section{Building a Better Method for Quality Ratings}

The intent of this commentary is to note the shortcomings of current models for ranking pharmacy schools and to call for development of a meaningful new method for publicly reporting on the quality of pharmacy schools. While the details of a new quality reporting system will require the input of many stakeholders and rigorous modeling and testing work to be conducted by measurement experts, we have identified potentially relevant data for consideration in the new quality measures.

An ideal measurement system will include multiple measures of quality. The NAPLEX pass rates for schools of pharmacy may be one reasonable measure within a

Table 1. Top Performing Schools of Pharmacy in the US News \& World Report Rankings

\begin{tabular}{|c|c|c|c|}
\hline USNWR & & NAPLEX & NAPLEX \\
\hline $\operatorname{Rank}^{\mathbf{b}}$ & School & $\overline{3-y r \text { Mean }^{a}}$ & $\overline{\text { Rank }}$ \\
\hline 1 & U North Carolina & 94.3 & 24 \\
\hline 2 & U Minnesota & 94.4 & 22 \\
\hline 3 & U Texas & 96.3 & 8 \\
\hline 3 & UC San Francisco & 95.2 & 15 \\
\hline 3 & U Michigan & 92.4 & 41 \\
\hline 6 & U Kentucky & 96.9 & 6 \\
\hline 6 & Ohio State U & 94.9 & 18 \\
\hline 6 & U Illinois Chicago & 89.2 & 65 \\
\hline 9 & U Washington & 97.8 & 2 \\
\hline 9 & U Wisconsin & 97.4 & 4 \\
\hline 9 & U Southern California & 96.3 & 9 \\
\hline 9 & U Pittsburgh & 92.5 & 40 \\
\hline 9 & U Florida & 91.8 & 47 \\
\hline 9 & Purdue U & 89.4 & 63 \\
\hline 9 & U Maryland & 88.5 & 69 \\
\hline
\end{tabular}

Abbreviations: USNWR =US News \& World Report,

NAPLEX $=$ North American Pharmacist Licensure Examination, $\mathrm{U}=$ University

${ }^{a}$ The NAPLEX pass rate was calculated as the mean of the firstattempt pass rates for each school in the years 2016 through 2018 as reported by the National Association of Boards of Pharmacy

$\mathrm{b}$ The USNWR rank was reported in 2016 based on a survey of deans in 2015
Table 2. The First-Attempt Pass Rates of the Top Performing Pharmacy Schools on the North American Pharmacist Licensure Examination

\begin{tabular}{|c|c|c|c|}
\hline School & $\frac{\text { NAPLEX }}{\text { 3-yr } \text { Mean }^{\mathrm{a}}}$ & $\frac{\text { NAPLEX }}{\text { Rank }}$ & $\frac{\text { USNWR }}{\text { Rank }^{\mathbf{b}}}$ \\
\hline South Dakota State U & 99.1 & 1 & 70 \\
\hline U Washington & 97.8 & 2 & 9 \\
\hline UC San Diego & 97.7 & 3 & 25 \\
\hline U Wisconsin & 97.4 & 4 & 9 \\
\hline U Houston & 97.0 & 5 & 44 \\
\hline U Kentucky & 96.9 & 6 & 6 \\
\hline Butler U & 96.6 & 7 & 47 \\
\hline U Texas & 96.3 & 8 & 3 \\
\hline U Southern California & 96.3 & 9 & 9 \\
\hline U Nebraska & 96.0 & 10 & 25 \\
\hline Thomas Jefferson U & 95.9 & 11 & 53 \\
\hline NEOMED & 95.9 & 12 & 66 \\
\hline U Puerto Rico & 95.8 & 13 & 88 \\
\hline U Tennessee & 95.4 & 14 & 17 \\
\hline UC San Francisco & 95.2 & 15 & 3 \\
\hline
\end{tabular}

${ }^{a}$ The North American Pharmacist Licensure Examination

(NAPLEX) pass rate was calculated as the mean of the first-attempt pass rates for each school in the years 2016 through 2018 as reported by the National Association of Boards of Pharmacy

b The US News \& World Report (USNWR) rank was reported in 2016 based on a survey of deans in 2015

quality rating system. Additionally, the AACP has a robust and efficient system for collecting quality-related data about schools of pharmacy. The AACP Assessment and Accreditation Management System (AAMS), along with the AACP survey system, prompt schools to collect and report a consistent set of quality indicators along with other information that may support quality improvement and accreditation reports. These systems are designed for benchmarking and trending in the pursuit of quality improvement, but the data are not easily available to the public. In fact, there are restrictions on the ability of a school to identify the data for a specific competitor (ie, only comparisons to the average for a group of schools are permitted).

The data within the AAMS system, including survey results, could be used along with the NAPLEX pass rates to create a quality rating system for schools of pharmacy. As schools are already collecting a consistent set of data and have a mechanism to efficiently report the data, these operational hurdles for a quality rating system have already been overcome. There will be great debate over which data should be included in the technical specifications for the quality measures of a pharmacy school and how a composite rating should be generated. Some may argue that surveys of graduating students are irrelevant or lack validity, while others may assert that the experiences of graduates is highly relevant and reasonably valid as a 


\section{American Journal of Pharmaceutical Education 2020; 84 (3) Article 7700.}

measure of quality. Of note, methods for implementing the AACP surveys have varied widely between schools and there is not currently a sufficient level of consistency between schools to enable an "apples to apples" comparison of survey results. If one of the AACP surveys were to become a component of a quality rating system, we anticipate that schools will take steps to increase the response rate on the survey.

There are numerous experts within academia and outside of academia who can gather the input of all stakeholders and conduct the research necessary for building and testing a composite measure of quality derived from quality-related data collected by AACP along with the NAPLEX pass rates. This composite measure of quality could be translated into a rating system that could be easily interpreted by the public. While data from AACP and NABP may be useful in constructing the measures of quality, it may be appropriate for an independent organization to conduct the analyses and provide the public reports. This may avoid any perceived conflict of interest from AACP evaluating its member institutions.

The biggest obstacle to creating a publicly reported composite measure of quality for PharmD programs will be the fears of academic leaders. As physicians, hospitals, nursing homes, and health plans entered the realm of public reports on quality, each of these groups expressed fear that their organization might not score well on the rating of quality. In other words, the professionals being rated have often fought the implementation of quality ratings by criticizing the validity of the rating and the potential burden for data collection (in addition to their repugnance of the idea that their "art" or "professional expertise" could be quantified). We expect that we would see the same pushback if a serious effort to deploy quality ratings of pharmacy schools were instigated.

Given the evolution of the healthcare system and societal demands for quality-related information, we believe the time is right for the profession of pharmacy and pharmacy academia to seriously consider a means to provide the public, particularly prospective applicants to PharmD programs, with a simple method for identifying and comparing the relative quality of PharmD programs. It is important for leaders in academia to engage in the development and deployment of these programs, lest we allow external entities to continue driving a ranking system that is publicly reported but lacks validity. While USNWR is the best known entity for ranking pharmacy schools, other organizations have released their own reports on pharmacy schools, and some of these reports do not provide transparency in how the ratings were constructed. ${ }^{11-13}$

The debate is likely to continue over the best methods for evaluating the quality of pharmacy schools. ${ }^{13-16} \mathrm{We}$ hope that academic pharmacy along with the profession of pharmacy are finally ready to work together to create a meaningful quality rating system for schools of pharmacy. The Academy's desire for a perfect measure should not stop us from continually improving methods to evaluate the quality of pharmacy education and providing meaningful information to potential applicants and employers.

\section{REFERENCES}

1. McKinsey \& Company. Assessing the Medicare Advantage star ratings. https://www.mckinsey.com/industries/healthcare-systemsand-services/our-insights/assessing-the-medicare-advantage-starsratings. Accessed May 23, 2019.

2. American Association of Colleges of Pharmacy. Profile of Pharmacy Students. https://www.aacp.org/research/student-applicationsenrollments-and-degrees-conferred.

3. Katie Zavadski. Why the pharmacy school bubble is about to burst. The New Republic. September 19, 2014. https://

newrepublic.com/article/119634/pharmacy-school-crisis-whygood-jobs-are-drying. Accessed May 23, 2019.

4. Health Resources Services Administration. The US health workforce chartbook. https://bhw.hrsa.gov/health-workforce-analysis/ research. Accessed May 23, 2019.

5. Pharmacy Workforce Center. Pharmacist demand index. https:// pharmacymanpower.com/. Accessed May 28, 2019.

6. National Association of Boards of Pharmacy. NAPLEX school passing rates. https://nabp.pharmacy/programs/naplex/score-results/. Accessed May 23, 2019.

7. ChangePharmacy.org https://www.change.org/p/protect-theprofession-we-honor-and-cherish-for-the-coming-decade-andbeyond. Accessed September 27, 2019.

8. US News \& World Report. Best pharmacy schools. https:// www.usnews.com/best-graduate-schools/top-health-schools/ pharmacy-rankings. Accessed May 23, 2019.

9. Ascione FJ. In pursuit of prestige: the folly of the US News \& World Report survey. Am J Pharm Educ. 2012;76(6):Article 103. 10. Mattingly TJ, Romanelli F, Cain J, Schlesselman LS. Measuring up - defining the quality of PharmD programs. Am J Pharm Educ. 2017;81(9):Article 6071.

11. Drugstore News. Head of the class: top pharmacy schools. https://www.drugstorenews.com/pharmacy/top-pharmacy-schools2018/. Accessed May 23, 2019.

12. SoFi. Pharmacy school rankings. https://www.sofi.com/blog/ refinance-student-loan-sofi-2017-pharmacy-school-rankings/. Accessed May 23, 2019.

13. Pharmacy Technician Guide. Best pharmacy schools in the US. https://www.pharmacytechnicianguide.com/Best-Pharmacy-

Schools.html\#Factors-taken-into-Account-for-our-Pharmacy-SchoolsRanking. Accessed May 23, 2019.

14. Maine LL, Vlasses PH. Assessing quality in pharmacy education in an era of rapid expansion. J Am Pharm Assoc. 2012;52(4):528-534. 15. Popovich NG, McCarthy RL, Roberts JC, Svensson CK, Sullivan DL. Assessing quality in pharmacy education in an era of rapid expansion: response to Maine and Vlasses. $J$ Am Pharm Assoc. 2013;53(3):228-232.

16. Maine LL, Vlasses PH. Assessing quality in pharmacy education in an era of rapid expansion: Response to Popovich et al. J Am Pharm Assoc. 2013;53(3):232-233. 